\title{
Managed Care and Technical Efficiency in Outpatient Substance Abuse Treatment Units
}

\author{
Jeffrey A. Alexander, Ph.D. \\ John R. C. Wheeler, Ph.D. \\ Tammie A. Nahra, M.A.E., M.H.S.A. \\ Christy Harris Lemak, Ph.D.
}

\begin{abstract}
This article examines (1) the extent to which managed care participation is associated with technical efficiency in outpatient substance abuse treatment (OSAT) organizations and (2) the contributions of specific managed care practices as well as other organizational, financial, and environmental attributes to technical efficiency in these organizations. Data are from a nationally representative sample survey of OSAT organizations conducted in 1995. Technical efficiency is modeled using data envelopment analysis. Overall, there were few significant associations between managed care dimensions and technical efficiency in outpatient treatment organizations. Only one managed care oversight procedure, the imposition of sanctions by managed care firms, was significantly associated with relative efficiency of these provider organizations. However, several organizational factors were associated with the relative level of efficiency including hospital affiliation, mental health center affiliation, JCAHO accreditation, receipt of lump sum revenues, methadone treatment modality, percentage clients unemployed, and percentage clients who abuse multiple drugs.
\end{abstract}

Managed care is steadily gaining acceptance as a financing and service delivery approach capable of controlling the rapidly increasing costs in mental health and substance abuse services. ${ }^{1-3}$ The primary mechanism underlying cost reduction in managed care is limiting use of services thought to be unnecessary for the effective treatment of mental health or substance abuse problems. Whereas the cost savings from decreased use of services can be documented relatively easily, ${ }^{4}$ managed care also is argued to encourage providers to improve the efficiency with which care is delivered. However, the relationship between managed care and the technical efficiency of providers has received little attention in empirical studies and policy debates. This study uses data envelopment analysis to examine the association of managed care practices; other organizational, financial, and environmental

Address correspondence to Jeffrey A. Alexander, Ph.D., Richard Carl Jelinek Professor, Department of Health Management and Policy, School of Public Health, University of Michigan, 109 South Observatory, Ann Arbor, MI 48109-2029; e-mail: jalexand@umich.edu.

John R. C. Wheeler, Ph.D., is a professor in the Department of Health Management and Policy, School of Public Health, University of Michigan.

Tammie A. Nahra, M.A.E., M.H.S.A., is a doctoral candidate in the Department of Health Management and Policy, School of Public Health, University of Michigan.

Christy Harris Lemak, Ph.D., is an assistant professor in the Health Services Administration, University of Florida. 
factors; and the technical efficiency of organizations that deliver outpatient substance abuse treatment (OSAT).

The specific aims of this article are (1) to describe the extent to which managed care participation is associated with technical efficiency in OSAT organizations and (2) to identify the contributions of specific managed care practices as well as other organizational, financial, and environmental attributes to technical efficiency in these organizations. Because the limited knowledge of managed care and its effects to date stems largely from the inability of past research to address the complexity and diversity of managed care arrangements, this study tests the effects of multiple dimensions of managed care oversight on the technical efficiency in OSAT units. Results of the study are intended to provide policy makers and OSAT administrators with evidence regarding how specific managed care practices affect the technical efficiency in treatment organizations.

\section{Conceptual Model}

There is a growing body of literature regarding the effects of managed care on health care costs. ${ }^{4-7}$ However, several limitations characterize this research. ${ }^{2}$ For example, although net cost reductions stemming from utilization review by a health maintenance organization may benefit an employer, some costs may be shifted to others including patients, their families, and providers. This study is concerned with one mechanism by which cost savings may be gained or lost under managed care: technical efficiency in the production of outpatient drug abuse treatment services.

For purposes of this article, managed care is defined as a set of public or private programs designed to control access to care, types of care delivered, or the amount and/or costs of care. Such programs incorporate a set of oversight activities used by, or on behalf of, purchasers of health care benefits to influence patient care decision making as it affects the aforementioned areas. ${ }^{5,8}$ Technical efficiency is defined as the use of specific input resources (e.g., staff hours and expenses) by an OSAT facility to provide specific outputs (e.g., therapy hours). A treatment organization is said to be technically efficient when it produces the maximum possible sustained output from a given set of inputs.'

Decisions that affect the relative efficiency with which a unit produces outpatient substance abuse therapy are potentially influenced by an array of factors. This study proposes that technical efficiency in provider organizations will be affected by managed care participation and managed care oversight requirements imposed on the provider organization as well as by other critical organizational, financial, and environmental factors. The rationales for these components of the conceptual model are discussed in the following sections.

\section{Managed Care Participation and Oversight}

As managed care firms seek to reduce costs, there are several ways in which provider organizations may be affected. ${ }^{2,8,10-13}$ These include fewer authorizations for inpatient treatment, shorter lengths of outpatient treatment, and reductions in the level of payments to providers. Managed care firms often emphasize case management, use patient assessment criteria and treatment protocols, and have rigorous standards for the documentation of treatment outcomes.

In practice, this means that OSAT units may be forced to provide shorter treatment programs, hire particular types of professional treatment staff, offer more group treatment, deemphasize or eliminate special programs, and better document treatment and follow-up to survive in the managed care environment. Managed care may, therefore, be associated with the technical efficiency of OSAT units in at least two ways. First, in light of the previous discussion about managed care, whether or not an OSAT unit participates in managed care may affect the technical efficiency of that organization. Second, among those organizations that do participate in managed care, technical efficiency may vary as a function of the scope and stringency of the activities used to manage care and costs. 
These activities, hereinafter referred to as managed care oversight procedures, will likely modify technical efficiency as a unit adjusts staffing allocations and therapy structure to meet managed care requirements and guidelines.

Managed care oversight refers to the mechanisms or controls imposed by the managed care organization on the provider to ensure that care is consistent with objectives of the managed care organization or its major clients. Generally, these procedures serve to control access to care and/or to regulate the amount, type, or quality of care. ${ }^{8}$ Managed care oversight activities may have both positive and negative effects on the technical efficiency of OSAT providers.

Because they are focused on treatment processes rather than treatment outcomes, managed care oversight activities have the potential to increase the technical efficiency of provider organizations. For example, treatment plans and utilization review may encourage the efficient use of treatment resources by mandating shorter treatment duration and requiring more coordination of the treatment process. Furthermore, it is generally accepted that variability in provider behavior is a source of inefficiency in the delivery of health services. ${ }^{14}$ As managed behavioral care firms reduce the variability in outpatient drug abuse treatment practices, they may improve the technical efficiency of treatment organizations.

Alternatively, however, managed care oversight procedures may decrease the technical efficiency of OSAT organizations in several ways. First, a reduction in the efficiency of organizational operations often occurs when behavioral controls are removed from the site of production. ${ }^{15}$ This may be true for OSAT providers because oversight requirements emanate from managed care firms that are physically removed from the site of service delivery. Second, managed care oversight activities often limit the range of services that are provided to clients (e.g., only group therapy) or specify the sequence of treatment options. Consequently, providers may lack the flexibility to treat clients in the most efficient manner. Finally, managed care oversight activities may increase requirements for administrative, accounting, or clerical record keeping on the part of the providers. In small organizations, these requirements might represent a burden that increases the inefficiency with which care is provided. $^{16}$

In addition to managed care participation, this study considers five managed care oversight activities and examines their association with technical efficiency. Each is discussed briefly in the following.

Specification of the treatment plan. Some managed care organizations dictate the content of treatment plans to the provider. ${ }^{17}$ Such requirements typically are imposed to allocate resources efficiently or to ensure that the level of quality of care is consistent with its cost.

Written utilization review. Utilization review includes pre-certification and ongoing authorization requirements that involve the approval of services before they are delivered or review of care at regular intervals. ${ }^{18}$ In such review, managed care organizations typically examine appropriateness of type and intensity of care for the patient's condition, judge the efficacy of the proposed treatment, and/or weigh issues such as medical necessity and client response to treatment.

Correspondence with treatment team member. The ease of handling the demands of managed care may vary as a function of who may communicate with the managed care organization for the purposes of utilization review. ${ }^{17}$ Some managed care arrangements require such communication to be with a member of the treatment team.

Visit limits. During the assessment and initial utilization review process, managed care arrangements may limit the number of visits or sessions authorized for payment. ${ }^{17}$ Provider organizations must demonstrate client progress or document more severe client problems for additional visits to be approved. These visit limits may hinder the ability of treatment staff to design the most efficient and effective course of treatment for managed care clients. 
Imposition of sanctions. Some managed care arrangements may review cases retrospectively and determine that certain services are not covered or exceed established limits or that services provided were not consistent with their objectives regarding cost or quality. Managed care firms may impose sanctions on providers by not paying for services if oversight requirements were not met or were not followed in a timely fashion.

\section{Other Internal and External Factors Associated with Technical Efficiency}

\section{Organizational Factors}

There exists significant variety in the respective affiliations and organizational structures of substance abuse treatment organizations. In this analysis, five organizational factors are examined: organizational setting, methadone treatment, ownership, accreditation, provision of nontherapeutic services, and client severity. Treatment units may be organized as freestanding programs or affiliated with larger institutions such as mental health centers and hospitals. Units also may practice varying treatment modalities such as the provision of methadone versus drug-free treatment. To the extent that such differences in staffing patterns and treatment practices influence the resource requirements for service delivery, they are likely to affect technical efficiency. ${ }^{19}$

Organizations may be categorized as either public, private not-for-profit (NFP) or private forprofit (FP). Property rights theory predicts that the incentives for efficiency tend to be weaker in public and NFP units, which lack clear owners and cannot distribute profits. ${ }^{20-22}$ Profit motive is theorized to create a strong incentive in FP units to monitor efficiency and restrain from self-enhancing objectives such as excess staff and slack time. ${ }^{20,23,24}$ Empirical findings for health care organizations have produced varied results regarding the impact of ownership on technical efficiency. ${ }^{20,25-27}$

Some OSAT units are accredited by the Joint Commission on the Accreditation of Healthcare Organizations (JCAHO). The effect of JCAHO accreditation is to improve quality by increasing the probability of desired patient outcomes and to reduce the probability of undesired outcomes. ${ }^{28}$ However, becoming JCAHO accredited requires a nontrivial commitment of resources and may, therefore, decrease the technical efficiency of units. ${ }^{29}$

Treatment organizations often offer a variety of services in concert with substance abuse treatment. The provision of these medical, educational, legal, or financial services may be utilitymaximizing activities that account for variations in technical efficiency. The scope and intensity with which services are provided may reflect the goals of the organization, the requirements of reimbursement agreements, or external pressure from the environment.

There is evidence that client problems and characteristics are differentially associated with treatment approaches. ${ }^{30}$ Previous research has shown that African American substance abusers more often suffer from more complex and multifaceted drug problems. ${ }^{30,31}$ In addition, clients who have a mental health problem in addition to their drug problem (dual diagnoses) and those clients who abuse more than one substance (multidrug users) are considered more complex or severe cases. These differences in client populations may affect technical efficiency because they often require additional types of treatment, special services, and coordination with other providers and agencies. ${ }^{30,31}$

\section{Financial Factors}

Throughout the past four decades, changing financial incentives have shifted the relative costs and benefits of providing services, altering the delivery and management of care. ${ }^{32}$ This study includes two financial factors that may affect technical efficiency: percentage of clients covered by insurance and percentage of revenues received in a lump sum. 
There are a variety of public and private insurance sources that employ various mechanisms of reimbursement including policies based on quantity of services provided, treatment episode, or capitation. Regardless of the insurance source or the specific reimbursement policy, the resulting impact is price distortion for the insured client. This price distortion may negatively affect the efficiency of a treatment unit. ${ }^{32}$

In addition to remuneration from an insurer or a self-pay client, substance abuse units may receive block grants or other lump sum payments that are not directly dependent on output therapy volume. This type of funding may encourage more efficient treatment as OSAT units strive to maximize their use of this source of revenue. Alternatively, block grant funding often is linked to the specific provision of nontreatment services such as outreach activities for vulnerable populations. Because resources must be allocated to these nontreatment activities and, therefore, redirected from patient therapy, lump sum payments may decrease the technical efficiency of the unit.

\section{Environmental Factors}

Environmental factors reflect external pressures to which an organization must respond to remain a viable participant in the marketplace. How responsive an organization will be to environmental factors will depend on the competitiveness of the marketplace and the adaptability, uniqueness, and necessity of services provided by the organization. This study considers three environmental factors: intensity of nonprice competition, number of local competitors, and urban versus rural setting.

Traditional economic theory postulates that highly competitive market structures influence producers to be more efficient than they would be under less competitive conditions or when assumptions of a competitive marketplace are violated. ${ }^{32}$ However, the impact of the environment may be more ambiguous in light of the potential nonprice competition that may exist among treatment units. Throughout the health care environment, nonprice competition has resulted in the supply of unnecessary services and amenities among managed care groups, ${ }^{33}$ excess capacity in hospitals, ${ }^{34}$ and overall inefficiencies in health care organizations. ${ }^{35}$ Within the treatment environment, the manifestation of nonprice competition for treatment units is reflected by staff credentials, physical attractiveness of the treatment setting, ease of access, quality of care, marketing efforts, and the range of services available.

The more treatment units there are in a market, the more incentive they have to compete, whether on a price or nonprice basis. All else equal, as the number of treatment units increases in a relevant market, the more nonprice competition becomes dominant. Also, units in rural settings have higher rates of excess capacity because they may have minimum staffing requirements without the consistent demand. ${ }^{36}$

\section{Data Envelopment Analysis}

As with most health care organizations, outpatient substance abuse providers are multiproduct firms. OSAT units provide a variable mix of individual, group, and family therapies, a fact that complicates evaluation of production efficiency. Parametric analytical approaches to measuring efficiency often require a single measure of production output. To overcome this and other limitations of parametric approaches, data envelopment analysis (DEA) is employed to analyze production efficiency in OSAT units.

Evaluating the efficiency of OSAT units requires the ability to identify "best practices," that is, the minimum set of inputs to provide therapy for a patient. Because the relationship between a unit's chosen inputs and outputs is complex, a method is necessary that can analyze efficiency and the nature of efficient relationships. ${ }^{20} \mathrm{DEA}$ is a nonparametric technique developed by Charnes, Cooper, and Rhodes that measures the rate of conversion of inputs into outputs in a multidimensional space. ${ }^{37.38}$ 
The advantage of employing DEA over parametric approaches is that this technique reveals a level of relative technical efficiency for all units without the need to impose a production function, assess the marginal productivity of inputs, or gather marginal cost information for the factors or products. ${ }^{39}$ Another advantage to DEA is that multiple inputs and outputs may be evaluated without the need for those measures to be dimensionally commensurate or additive. ${ }^{38}$

DEA uses linear programming methodology to define a production horizon for decision-making units; the standard for optimality that defines the production horizon (also referred to as the best practice production frontier) is derived from observed data instead of a theoretical construct. The mathematical model and theoretical base of DEA are described in other articles. ${ }^{20,37,40,41}$ The DEA model employed in this study is based on the original work of Charnes, Cooper, and Rhodes that estimates a piecewise linear surface with constant returns to scale.

For each OSAT unit, DEA measures the magnitude of departure from the production horizon based on the unit's use of resources to produce multiple outputs. ${ }^{20}$ The DEA measure for those units defining the production horizon is assigned a score of 1 ; less efficient units are assigned a score less than 1 based on their relative positioning in relation to the production horizon. Therefore, those units that produce far fewer outputs for a given set of inputs would have a much lower DEA score than those units that produce closer to the best practice production frontier for a similar input combination.

Reflecting the relative efficiency of each unit, these DEA scores serve as the dependent variable in the second part of the analysis, which identifies the key determinants of technical efficiency of OSAT units.

\section{Methods}

\section{Sample}

This study uses data from a 1995 national survey of OSAT units conducted by the University of Michigan's Institute for Social Research (ISR). To qualify for the study, at least $50 \%$ of the treatment services provided by these organizations must have been for drug abuse problems, and most drugrelated services must have been provided on an outpatient basis.

A systematic random sample of OSAT units was selected for participation from the 1994-95 National Frame of Substance Abuse Treatment Programs (NFSATP), a national database of inpatient and OSAT programs compiled by the ISR in 1994. The national database, serving as a sampling frame, consists of 32,927 treatment units, making it the most complete listing available of the nation's OSAT units. ${ }^{42}$ This list is a composite developed from five separate sources that were merged and unduplicated. These sources are as follows: 1992 National Facilities Register, 1992 National Drug and Alcoholism Treatment Unit Survey, 1994 American Hospital Association Survey, 1994 Food and Drug Administration list of licensed methadone providers, and a complete national database of businesses with a Standard Industrial Classification Code for Drug and Alcohol Treatment Services.

The sample was stratified by public/private status, treatment modality (methadone or nonmethadone), and organizational affiliation (e.g., hospital, mental health center). OSAT units operated by the Veterans Administration and by jails or prisons were excluded from the study. After screening and nonresponse, the total number of organizations completing interviews in 1995 was 618 , for a combined response rate of $88 \%$. $^{42}$

Some of the units in the sample provided services that were not related to substance abuse treatment. To ensure that the respective measures for the inputs and outputs were primarily dedicated to substance abuse treatment, only those units in which at least $75 \%$ of both clients and revenues were related to substance abuse treatment services are included in these analyses. This criterion permitted the development of an accurate and valid measure of technical efficiency as well as a way in which to 
balance the simultaneous issues of representing the nation's outpatient treatment system and achieving sufficient statistical power. Of the 618 units, 474 units met this criterion. The OSAT units in the study's national sample are small to medium-sized organizations (mean full-time equivalents $=15$ ) that treat, on average, 600 clients per year. While most of the units are freestanding or unaffiliated, $17 \%$ are affiliated with a hospital and $15 \%$ are affiliated with a mental health center. A large proportion of the organizations (62\%) are private FP units. On average, sample OSAT units treat a client base that is $33 \%$ female and $25 \%$ African American. Clients in treatment in these organizations abuse a variety of drugs including heroin (average $24 \%$ of clients) and cocaine (average $22 \%$ of clients). Additional sample characteristics are shown in Table 1.

\section{Survey Method}

The administrative director and clinical supervisor of each participating OSAT unit were asked to complete phone surveys. Directors provided information concerning the unit's ownership, environment, finances, parent organizations, and managed care arrangements. Clinical supervisors provided information about staff, clients, and services provided.

Several steps were followed to produce reliable and valid phone survey data including site visits, two pretests of the instruments, elaborate interviewer training, extensive checks for consistency within and among instrument sections, and (when necessary) re-contacts with respondents. ${ }^{43}$

\section{Dependent Variable}

The DEA score was used as the dependent variable in the analyses. As noted by Magnussen, ${ }^{39}$ reliability of the DEA score is dependent on the input and output vectors used. Therefore, to test the robustness of the DEA scores, various combinations of inputs and outputs were entered into the model, keeping the number of inputs and outputs constant. $K$-means rank sum test grouped the units by their respective efficiency level for these various input and output vectors. The ranked grouping into which a unit fell (five efficiency levels ranging from high to low) remained constant in $90 \%$ of the cases.

Four input categories were used in the DEA model: full-time staff hours, part-time staff hours, consultant hours, and normalized expenditures. These inputs capture the labor and capital resources dedicated to the production of substance abuse therapy. Full-time staff hours and part-time staff hours reflect the time dedicated to the OSAT unit by employees who provide therapeutic, administrative, or clerical services. Consultant hours capture those hours provided by external consultants or contractors who supplement the OSAT staff with therapeutic, administrative, or clerical services.

Total expenditures were normalized using the Medicare operating and capital indexes for geographic adjustment. ${ }^{44}$ Operating and capital portions of total expenses were adjusted by either metropolitan statistical area (MSA) or state, depending on the location of the unit. The total normalized expenses capture two features of the unit's inputs. First, it captures the capital expenditures of the unit that are a critical part of a unit's ability to provide various services. In addition, because wages are normalized, those units that employ "richer" resources will have higher overall normalized expenses. These "richer" resources may theoretically lead to higher technical efficiency, thus adding valuable information to the DEA.

Therapy hours were used to represent a quantifiable, homogeneous output in the unit's production function. The use of therapy hours as a measure of output is supported by other studies that show that some form of drug abuse counseling or psychotherapy is used in $99 \%$ of all drug treatment units. ${ }^{45}$ Three output categories were used to capture the breadth of outpatient therapy services: individual therapy hours, group therapy hours, and family therapy hours. Individual and family therapy hours per week were taken directly from the survey. Total group therapy hours per week were calculated using group therapy hours per week per client multiplied by the number of clients per group session. 


\section{Affiliation}

Hospital

Mental health center

Freestanding or other affiliation

Ownership status

Private for-profit

Private not-for-profit

Public

Modality

Provide methadone treatment

Geographic region

Midwest

Northeast

South

West

Have Joint Commission on the Accreditation

of Healthcare Organizations accreditation

Participate in managed care

Total staff (full-time equivalents)

Total clients per year

Number of years in business

Mean percentage $e^{a}$ of clients who

Abuse heroin

Abuse cocaine

Abuse multiple drugs

Have dual diagnoses

Are women

Are African American

a. Percentages do not sum to 100 because categories are not mutually exclusive.

\section{Independent Variables}

A total of 21 independent variables were used in the analyses to model the relationship between managed care and technical efficiency. These variables may be grouped into four categories: managed care, organizational factors, financial factors, and environmental characteristics. Descriptive statistics and source information for each of these variables are found in Table 2; bivariate correlations are displayed in Table 3. 


\begin{tabular}{|c|c|c|c|}
\hline Variable & Range & Mean & $\begin{array}{l}\text { Standard } \\
\text { Deviation }\end{array}$ \\
\hline \multicolumn{4}{|l|}{ Managed care participation } \\
\hline More than 10 clients in MCAs $(1=$ yes $)$ & $0-1$ & 0.37 & 0.48 \\
\hline \multicolumn{4}{|l|}{ Managed care oversight activities } \\
\hline Percentage clients for whom MCAs specify treatment plans & $0-100$ & 4.45 & 13.83 \\
\hline $\begin{array}{l}\text { Percentage clients for whom MCAs require written } \\
\text { utilization review }\end{array}$ & $0-100$ & 3.98 & 11.88 \\
\hline $\begin{array}{l}\text { Percentage clients for whom MCAs require correspondence } \\
\text { with treatment team }\end{array}$ & $0-100$ & 6.21 & 16.54 \\
\hline Percentage clients for whom MCAs impose visit limits & $0-100$ & 8.56 & 20.10 \\
\hline Percentage clients for whom MCAs impose sanctions & $0-100$ & 3.33 & 11.05 \\
\hline \multicolumn{4}{|l|}{ Organizational factors } \\
\hline Setting: Unit is affiliated with a hospital (1 = yes) & $0-1$ & 0.17 & 0.38 \\
\hline Setting: Unit is affiliated with a mental health center $(1=$ yes $)$ & $0-1$ & 0.15 & 0.36 \\
\hline Unit provides methadone treatment $(1=$ yes $)$ & $0-1$ & 0.24 & 0.43 \\
\hline Ownership: Unit is private for-profit $(1=$ yes $)$ & $0-1$ & 0.14 & 0.35 \\
\hline Ownership: Unit is private not-for-profit $(1=$ yes $)$ & $0-1$ & 0.62 & 0.48 \\
\hline \multicolumn{4}{|l|}{ Unit has Joint Commission on the Accreditation of Healthcare } \\
\hline Organizations accreditation $(1=$ yes $)$ & $0-1$ & 0.22 & 0.42 \\
\hline Intensity of nontherapy services offered by unit ${ }^{\mathrm{a}}$ & $0-1615$ & 280.59 & 265.59 \\
\hline Client severity: Percentage clients African American & $0-100$ & 24.51 & 26.27 \\
\hline Client severity: Percentage clients with dual diagnoses & $0-100$ & 26.91 & 22.01 \\
\hline Client severity: Percentage clients who abuse multiple drugs & $0-100$ & 69.72 & 28.63 \\
\hline \multicolumn{4}{|l|}{ Financial factors } \\
\hline $\begin{array}{l}\text { Percentage clients with some insurance (public or } \\
\text { private sources) }\end{array}$ & $0-100$ & 33.45 & 32.94 \\
\hline Percentage revenues in lump sumb & $0-100$ & 22.79 & 30.03 \\
\hline \multicolumn{4}{|l|}{ Environmental factors } \\
\hline Level of nonprice competition ${ }^{\mathfrak{c}}$ & $1-5$ & 2.57 & 0.87 \\
\hline $\begin{array}{l}\text { Number of substance abuse providers in the } \\
\text { county (competitors) }\end{array}$ & $0-100$ & 118.36 & 185.59 \\
\hline $\begin{array}{l}\text { Unit is in urban area (metro or fringe counties }>1 \text { million } \\
\text { population) location }(1=\text { yes })\end{array}$ & $0-1$ & 0.53 & 0.50 \\
\hline
\end{tabular}

NOTE: $\mathrm{MCAs}=$ managed care arrangements.

a. Sum of the number of medical, social, and other support services offered (31 possible services) times average percentage of clients receiving each service.

b. Lump sum payments include block grants and other special funds from government and private sources. c. Composite of six questions regarding extent to which competition with other units is based on issues other than price (staff credentials, setting, ease of access, quality of care, marketing efforts, range of treatment approaches).

\section{Statistical Methods}

The regression method for analyzing the determinants of efficiency followed a two-part estimation procedure. The motivation for employing this technique came from an examination of the 


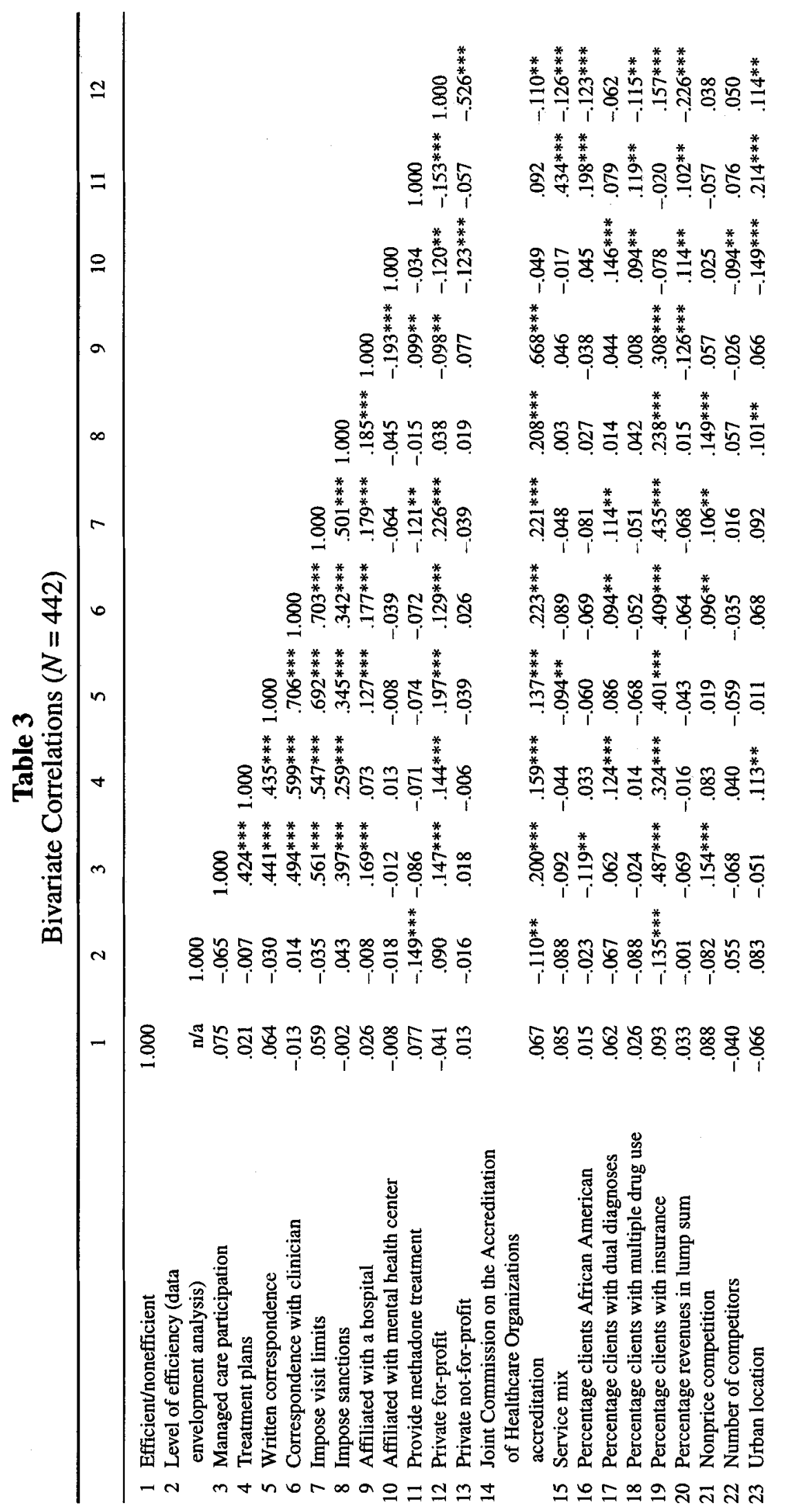




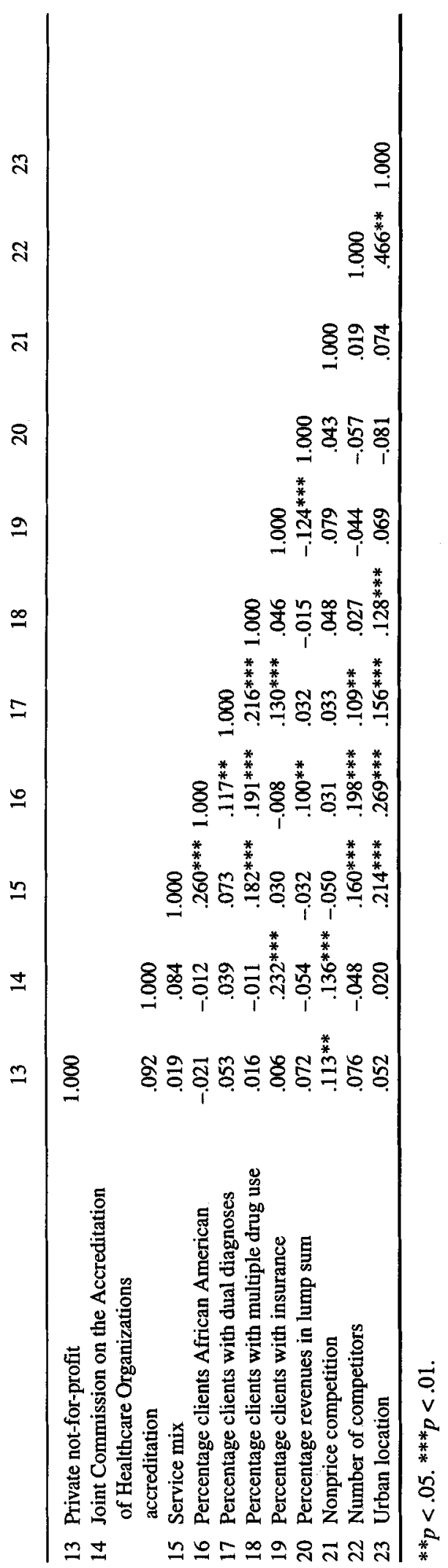


dependent variable. The DEA scores for OSAT units that are characterized as inefficient fall into a wide spectrum of strictly positive values that are less than 1 . Since the DEA has an upper value limit of 1 , those OSAT units that are efficient and define the production horizon are clustered at $1 .^{20}$ Because of this upper bound limit at 1, the DEA score is a censored distribution. With a censored distribution, there lacks a discriminatory score for units at the upper bound; all values above 1 are transformed to (or reported as) a single value. Consequently, a regression model other than ordinary least squares (OLS) is required since OLS yields asymptotically biased estimators when the dependent variable is censored. ${ }^{46}$

The efficient units are said to be "selected" into a subsample since their respective DEA scores are not completely observed but instead are assigned a value of 1 . Censored sample selection models account for the impact of this "selection" process by modeling the process in two stages. In the first stage, a dichotomous variable determines whether or not the dependent variable is observed. ${ }^{47}$ In this study, the first stage determines whether or not a unit is deemed relatively efficient or inefficient and is modeled as a probit equation. In the second stage, the expected value of the dependent variable is modeled, conditional on its having been observed. ${ }^{47}$ The correlation between the two stages is explicitly modeled and is included as an explanatory variable in the second equation, which is estimated using OLS and includes a selection factor. ${ }^{46}$

To complete the two-step estimation, the Heckman procedure was applied using LIMDEP software (Econometric Software, Bellport, New York). Using the coding scheme required by LIMDEP, the inefficient units were recoded equal to 1 (those that are selected into the sample because of complete DEA scores) and the efficient units were recoded equal to 0.

\section{Results}

The initial stage of the DEA involved determination of the relative efficiency of the OSAT units. Given the distribution of the DEA variable, a dichotomous variable was created that identified units that were, relative to other units in the sample, the most technically efficient. Based on the DEA scores, 30 of the $442 *$ units were assigned an efficiency score of 1.00 , and another 13 units were within the top $90 \%$ for efficiency. These 43 "efficient" units had scores ranging from 1.00 to 81 , with a mean of .96 . The remaining 399 units had scores ranging from .79 to .02 , with a mean of .31. The dichotomous efficiency variable, therefore, had 43 units with a value of 1 and 399 units with a value of 0 .

The Heckman model used this created dichotomous variable as the dependent variable in the first-stage probit model. The actual DEA score was then used as the dependent variable in the second stage, where the determinants of the relative level of efficiency were evaluated. The first stage of the model is presented in Table 4, and the second stage of the model is presented in Table 5.

In the first-stage probit model, the log-likelihood ratio test (chi-square $=29.69, d f=21, p<.10$ ) indicated a fairly good fit to the data. Four variables in the model were statistically significant in the prediction of efficient versus nonefficient OSAT units. As predicted, nonprice competition decreased the probability that a unit would be efficient $(p<.01)$. The necessity of written utilization review also decreased the likelihood that a unit would be efficient $(p<.10)$. The urbanicity indicator was positive and significant $(p<.10)$, suggesting that urban units were likely to have less excess capacity and, therefore, higher efficiency than their rural counterparts. Managed care requirements that require that correspondence regarding utilization review be conducted with a member of the treatment team also increased the likelihood that a unit was efficient $(p<.05)$.

\footnotetext{
* Listwise deletion of missing values reduced the sample size from 474 possible cases to approximately 442 valid cases in the data envelopment analysis (DEA). Cases lost to missing items were compared to those used in the analysis, using independent sample $t$ tests. Comparisons were made by strata for treatment hours per staff hours, treatment hours per clinical staff hours, and staffing expenditures as a percentage of total expenditures. No significant differences were found between the missing cases and those used in the DEA.
} 


\section{Table 4}

Results of First-Stage (PROBIT) Model: Predicting Efficient versus Nonefficient Outpatient Substance Abuse Treatment Units

\begin{tabular}{|c|c|c|}
\hline Variable & Coefficient & Standard Error \\
\hline Constant & $-3.92 \mathrm{E}-01$ & 4.04E-01 \\
\hline Managed care participation & $-1.34 \mathrm{E}-01$ & 2.72E-01 \\
\hline \multicolumn{3}{|l|}{ Managed care oversight activities } \\
\hline Specify treatment plans & $-1.39 \mathrm{E}-02$ & $1.26 \mathrm{E}-02$ \\
\hline Require written utilization review & $-2.94 \mathrm{E}-02 *$ & $1.76 \mathrm{E}-02$ \\
\hline Require correspondence with treatment team & $2.66 \mathrm{E}-02 * *$ & 1.11E-02 \\
\hline Impose visit limits & $-8.77 \mathrm{E}-03$ & $9.65 \mathrm{E}-03$ \\
\hline Impose sanctions & $1.28 \mathrm{E}-02$ & $1.14 \mathrm{E}-02$ \\
\hline \multicolumn{3}{|l|}{ Organizational factors } \\
\hline Affiliated with a hospital & $3.62 \mathrm{E}-01$ & 3.63E-01 \\
\hline Affiliated with a mental health center & $1.92 \mathrm{E}-01$ & $2.80 \mathrm{E}-01$ \\
\hline Provide methadone treatment & $-3.68 \mathrm{E}-01$ & $2.76 \mathrm{E}-01$ \\
\hline Private for-profit & $2.20 \mathrm{E}-01$ & $3.29 \mathrm{E}-01$ \\
\hline Private not-for-profit & $-6.49 \mathrm{E}-02$ & $2.35 \mathrm{E}-01$ \\
\hline \multicolumn{3}{|c|}{ Joint Commission on the Accreditation of Healthcare } \\
\hline Organizations accreditation & $-3.39 \mathrm{E}-01$ & $3.40 \mathrm{E}-01$ \\
\hline Intensity of nontherapy services & $-5.70 \mathrm{E}-04$ & 4.64E-04 \\
\hline Percentage clients African American & $1.03 \mathrm{E}-03$ & $3.62 \mathrm{E}-03$ \\
\hline Percentage clients with dual diagnoses & $-4.27 \mathrm{E}-03$ & $4.56 \mathrm{E}-03$ \\
\hline Percentage clients who abuse multiple drugs & $2.27 \mathrm{E}-03$ & $3.23 \mathrm{E}-03$ \\
\hline \multicolumn{3}{|l|}{ Financial factors } \\
\hline Percentage clients with some insurance & $-3.77 \mathrm{E}-03$ & $3.51 \mathrm{E}-03$ \\
\hline Percentage revenues in lump sum & $-7.40 \mathrm{E}-04$ & $3.21 \mathrm{E}-03$ \\
\hline \multicolumn{3}{|l|}{ Environmental factors } \\
\hline Nonprice competition & $-2.99 \mathrm{E}-01 * * *$ & $1.15 \mathrm{E}-01$ \\
\hline Number of competitors & 1.72E-04 & 4.93E-04 \\
\hline Urban location & $3.81 \mathrm{E}-01^{*}$ & $2.29 \mathrm{E}-01$ \\
\hline$N$ & $435^{\mathfrak{a}}$ & \\
\hline Log likelihood & -120.99 & \\
\hline Restricted log likelihood & -135.83 & \\
\hline Chi-square $(d f=21)$ & $29.69 *$ & \\
\hline
\end{tabular}

NOTE: All values are displayed using scientific notation to improve readability. For example, "E-01" is an abbreviation for the exponent field " $\times 10^{-1}$."

a. Listwise deletion of missing values reduced the sample from 442 possible cases to 435 valid cases. The cases lost to missing items were compared to those used in the analysis using independent sample $t$ tests. No significant differences were found.

${ }^{*} p<.10 .{ }^{* *} p<.05 .{ }^{* * *} p<.01$.

The second stage of the selection model analyzed the efficiency for 399 units. Of the five managed care oversight procedures, only one, the imposition of sanctions, was found to have a significant and positive impact on the level of technical efficiency $(p<.10)$. The four other managed care 


\section{Table 5}

Results of Second-Stage (ordinary least squares) Heckman

Estimation Model: Predicting Level of Technical Efficiency in Outpatient Substance Abuse Treatment Units

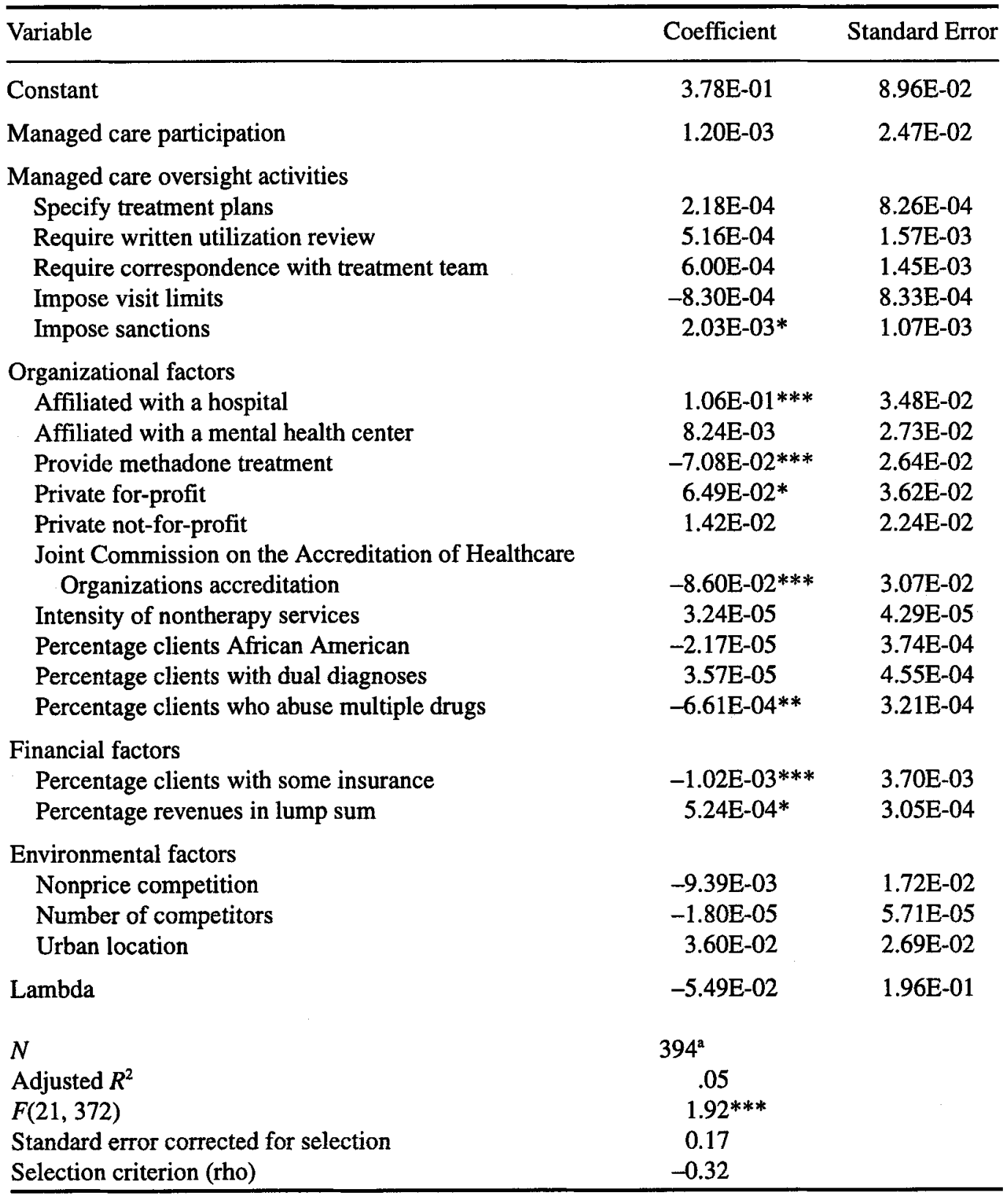

NOTE: All values are displayed using scientific notation to improve readability. For example, "E-01" is an abbreviation for the exponent field " $\times 10^{-1}$."

a. This represents only units deemed "inefficient" by the data envelopment analysis.

${ }^{*} p<.10 .{ }^{* *} p<.05 .{ }^{* * *} p<.01$. 
oversight procedures and the managed care participation indicator were not found to be significantly associated with technical efficiency.

As predicted, several organizational characteristics were found to make statistically significant contributions to the prediction of the level of technical efficiency. Affiliation with a hospital had a significant positive impact $(p<.01)$, which may indicate that economies of scale and scope are at play. Units associated with hospitals may have assistance from other nonsubstance abuse departments with support capabilities such as patient scheduling, billing, and other administrative functions. Freed from such nontherapy activities, the treatment staff may then conduct more therapy sessions, leading to relatively higher levels of efficiency.

Affiliation with a mental health center also was positively associated with efficiency, although not significantly. The provision of methadone treatment significantly decreased the relative efficiency of units $(p<.01)$. This may be explained by the method these units use to provide treatment for their clients. Although the administration of methadone doses involves direct patient contact, a unit may not classify this as patient therapy. Because the administration of methadone is considered a nontherapy activity, methadone units might, therefore, be less likely to provide the same relative therapy hours (output) for a given level of staff (input).

FP ownership also was significantly associated with higher levels of technical efficiency $(p<.10)$. This finding, mirrored in many studies of health care organizations, may reinforce the theory of property rights and the incentive for these units to restrain from nontherapeutic activities.

JCAHO accreditation significantly decreased the efficiency of a unit $(p<.01){ }^{29}$ As noted, accreditation requires a commitment on the part of the staff for nontrivial amounts of documentation and procedural activities. This would require additional staffing resources and, therefore, would decrease those committed to therapy hours.

Financial arrangements also affected efficiency significantly. Units with higher percentages of insured clients were less likely to be efficient $(p<.01)$. Insured clients might feel less restricted financially to demand more nontherapeutic services, higher quality, and richer staffing resources, all of which would decrease the technical efficiency for the unit. Revenues received in a lump sum were positively associated with efficiency $(p<.10)$.

The only client characteristic that affected efficiency was the percentage of clients who abuse multiple drugs. As predicted, the existence of more clients with multiple addictions led to lower levels of technical efficiency $(p<.01)$. These clients may require more nontherapeutic interventions and administrative tracking. Also, although not significant, a higher percentage of African American clients was associated with lower levels of efficiency, which supports previous research findings.

None of the variables representing environmental characteristics was significantly associated with the relative level of technical efficiency.

\section{Implications for Behavioral Health Services}

Results from these analyses indicate that managed care participation is not significantly related to the level of efficiency of the OSAT units. This may suggest that managed care firms do not select substance abuse treatment providers that are most efficient, nor do they create incentives for providers to improve the efficiency of their operations. This finding also reinforces the concern that only measuring participation in managed care might mask considerable variation in the nature of managed care interventions and their likely effects. Variables that allow for more detailed understanding of the complexity and diversity of managed care interventions, like those included in this analysis, are important to consider.

Only three of the detailed measures of managed care oversight, however, are associated with either the likelihood of being efficient or the level of inefficiency, and two of these show weak association. There are two general explanations for these results: Either (1) managed care may influence 
provider efficiency in complex and conflicting ways or (2) managed care has not yet influenced the market for substance abuse treatment.

Regarding this first potential explanation, the specific managed care oversight activities considered have the potential to reduce organizational inputs and organizational outputs independently. For example, managed care oversight activities may decrease organizational inputs (treatment staff time) by adding to administrative work requirements. Simultaneously, managed care may stimulate the provider organizations to search for opportunities to reduce inefficiency through staff reductions and other means, which could decrease organizational outputs (therapy hours). In the organizations observed in this study, each of these effects may be operating simultaneously, so that no large net effect of managed care is observed in either direction.

Alternatively, because they focus on reducing inappropriate use, managed care oversight procedures also have the potential to reduce client load. If this occurs, then OSAT units may correspondingly reduce inputs as they attempt to match resources with service demands. As a result of adjusting both inputs and outputs, organizations might not observe an improvement in either staffing ratios or relative technical efficiency.

The second potential explanation, that managed care does not yet influence substance abuse treatment, is difficult to evaluate given the possibilities already cited. This study has not investigated whether the oversight activities are related to changes in service utilization, as has been shown to be the case for general medical care services. ${ }^{49}$ However, the fact that participation in managed care is not associated with improvements in technical efficiency is surprising. One would expect providers in managed care markets to work for the cost reductions resulting from efficiency improvements as purchasers begin more effectively to constrain payments for services. What is not known yet is whether managed care has affected the types of payment reductions for substance abuse services that have occurred in the general medical care sector.

The fact that several organizational characteristics are associated with level of inefficiency in plausible directions lends credibility to the measure of technical efficiency in this study. These results also demonstrate that many of the organizational relationships found for hospitals and other health care providers also hold for substance abuse providers.

FP providers had higher levels of efficiency, a finding consistent with the results of previous studies of substance abuse providers ${ }^{21}$ as well as of studies of hospitals. ${ }^{50}$ Whether the efficiency gains made by FP providers translate to reductions in prices paid and how these gains might be related to accessibility should be the subject of future research.

The percentage of clients with health insurance is associated with lower efficiency. Again, this finding is consistent with research showing that health insurance raises prices and costs in medical care generally. The importance of the result here is to document that substance abuse providers behave in a similar fashion to other medical care providers in the presence of insurance for their services.

Substance abuse units affiliated with hospitals are, on average, more efficient. This finding is at odds with the general perception that hospital-based units, for all types of services, are more expensive than freestanding units. What is different about this research is that it has focused on the efficiency of direct service provision rather than on reported costs. In our study, hospital-affiliated units employed fewer clinicians, other personnel, and other production inputs than freestanding units. But these same hospital-based units may report higher costs because of the overhead costs of operating a hospital or if employees of hospitals receive higher compensation than do workers in freestanding units.

Closely related to hospital affiliation is JCAHO accreditation. ${ }^{29}$ Accredited units are less efficient than those not accredited. The JCAHO accreditation program is widely accepted as increasing cost while bringing about some increased level of quality in the system. Results from this show that the cost implications of accreditation extend to substance abuse treatment units. 
This study has several implications for managers of OSAT units. First, there is variation in technical efficiency among OSAT providers. While there is not yet evidence that technical efficiency is a selection criterion used by managed behavioral care organizations, the selection criteria for participation may become more sophisticated as managed behavioral care penetration increases. This may make technical efficiency an increasingly salient managerial concern. Second, managers should consider how specific oversight activities may affect the technical efficiency of their units when negotiating contracts with managed behavioral care organizations. For example, stringent utilization review requirements could make it difficult for units to achieve technical efficiency.

This study also indicates that some OSAT managers might be responding to the incentives of payment systems other than those of managed care. For example, units with large numbers of insured clients are somewhat less efficient, perhaps because they offer more amenities to attract insured clients. This speculation is consistent with the finding that nonprice competition reduces the likelihood that a unit will operate efficiently. If managed care organizations begin to emphasize improved efficiency, then these units might find it difficult to continue offering amenities. Furthermore, those units accredited by the JCAHO are less efficient than nonaccredited units. In the future, managers might find it increasingly difficult to balance the requirements of accreditation with efficiency standards that may be imposed by managed care. Finally, study results suggest that investor-owned units have been more successful in the area of technical efficiency. Accordingly, these investor-owned units might have an advantage over public and NFP units if managed care does place greater demands on OSAT units for improved efficiency.

\section{Limitations and Areas for Future Research}

The preceding discussion of the research findings should be tempered by the following limitations. First, technical efficiency of multiproduct firms may be measured in a variety of ways. The DEA score could have been constructed using other organizational inputs such as capital equipment or professional treatment staff hours. Similarly, the output components of the DEA score could have included some measure of rehabilitated clients, other quality measures, or unit recidivism rates. Second, the study could not consider all possible dimensions of managed behavioral care that may be associated with levels of technical efficiency. For example, case management activities, benefit package design, and the structure of provider reimbursement were not included in the current analysis.

The authors' decision to exclude treatment units in which OSAT represents less than $75 \%$ of total clients or revenues might limit somewhat the generalizability of the findings. This criterion was selected to balance the issues of (1) representing the nation's OSAT system, (2) the development of an accurate and valid measure of the technical efficiency of OSAT units, and (3) achieving sufficient statistical power. It is possible, therefore, that relationships between managed care and technical efficiency may be different for organizations that are not primarily dedicated to OSAT services including those that have changed their service offerings in response to managed care and those that are affiliated with mental health centers and hospitals. In general, however, the carefully constructed sampling frame and nationally representative sample of OSAT units suggest that the relationships identified in this study are likely to apply to the majority of provider organizations in the nation's outpatient treatment system.

Use of DEA to estimate efficiency of production has both supporters and detractors. ${ }^{39,51}$ The technique can be helpful in analyzing the production of substance abuse services because the producers typically were providing a mix of services difficult to measure along a single dimension. Study results for organizational and client mix characteristics generally support the validity of the approach in this situation. However, the weak results for the managed care variables raise some doubts. As a check on the use of the DEA method, results of the DEA analysis were compared to the 
typically were providing a mix of services difficult to measure along a single dimension. Study results for organizational and client mix characteristics generally support the validity of the approach in this situation. However, the weak results for the managed care variables raise some doubts. As a check on the use of the DEA method, results of the DEA analysis were compared to the results of analyses using more simple measures of labor productivity. In general, conclusions were similar.*

While this article has shed some light on how substance abuse treatment providers are responding to managed care, some important questions remain unanswered. In particular, little is known about whether and how client programs of care are being altered because of managed care programs. Subsequent research should focus on the effects managed care might have on duration and style of treatment for substance abuse clients.

Despite the issues just discussed, this study contributes to the understanding of managed behavioral health care by rigorously examining the relationship between key characteristics of managed behavioral care and technical efficiency of OSAT providers. The use of a nationally representative sample, advanced analytic techniques, and multiple dimensions of managed care represent clear advances in this line of inquiry.

\section{Appendix \\ Data Envelopment Models Used}

The following model was used to reveal the overall technical efficiency for each of the 442 outpatient substance abuse treatment (OSAT) units: ${ }^{52}$

$$
\operatorname{Max} E_{k}=\sum_{r=1}^{s} u_{r} Y_{n k} / \sum_{i=1}^{m} v_{j} X_{i k}
$$

subject to the constraint:

$$
\begin{array}{rlrl}
{\left[\sum_{r=1}^{s} u_{r} Y_{r j} / \sum_{i=1}^{m} v_{i} X_{i j}\right]} & \leq 1 & \mathrm{j}=1, \ldots, n \\
u_{r} & \geq 0 & r=1, \ldots, s \\
v_{i} \geq 0 & i=1, \ldots, m
\end{array}
$$

where

$E_{k}=$ the measure of efficiency for OSAT unit $k$, the member of the set of $j=1, \ldots 442$ OSAT units rated relative to the others;

$Y_{r k}=$ the known amount of output $r$ produced by the OSAT unit $k$ during the period of observation;

$X_{i k}=$ the known amount of input $i$ used by the OSAT unit $k$ during the period of observation;

$Y_{r j}=$ the known amount of output $r$ produced by the OSAT unit $j$ during the period of observation;

$X_{i j}=$ the known amount of input $i$ used by the OSAT unit $j$ during the period of observation;

$u_{r}=$ the coefficient or weight assigned to output $r$ computed in the solution to the data envelopment analysis (DEA) model;

\footnotetext{
* Simple measures of labor productivity were used in place of the data envelopment analysis efficiency score in a similar set of analyses. These labor productivity measures, which served as dependent variables in separate analyses, included total professional hours per total outpatient substance abuse treatment (OSAT) therapy hours, total professional hours per individual OSAT therapy hours, and total staff hours (professional and administrative) per total OSAT therapy hours.
} 
$v_{i}=$ the coefficient or weight assigned to input $i$ computed in the solution to the DEA model;

$n=$ the number of OSAT units;

$m=$ the number of inputs used by the OSAT units; and

$s=$ the number of outputs produced by the OSAT units.

The objective function of this model maximizes the efficiency rating $E$ for OSAT unit $k$. This is subject to the constraint that when the same set of $u$ and $v$ coefficients are applied to all other OSAT units being compared, no OSAT unit will be more than $100 \%$ efficient and the coefficient values are positive. $^{20,51}$

\section{Acknowledgment}

This research was supported by grants (Nos. 5R01-DA03272 and 5R01-DA087231) from the National Institute on Drug Abuse.

\section{References}

1. Iglehart JK: Managed care and mental health. New England Journal of Medicine 1996; 334:131-135.

2. Mechanic D, Schlesinger M, McAlpine DD: Management of mental health and substance abuse services: State of the art and early results. Milbank Quarterly 1995; 73:19-55.

3. Sederer LI, Bennett MJ: Managed mental health care in the United States: A status report. Administration and Policy in Mental Health 1996; 23:289-306.

4. Miller RH, Luft HS: Managed care plan performance since 1980: A literature analysis. Journal of the American Medical Association 1994; 271:1512-1519.

5. Institute of Medicine: Controlling Costs and Changing Patient Care? The Role of Utilization Management. Washington, DC: National Academy Press, 1989.

6. Luft H: Health Maintenance Organizations: Dimensions of Performance. New Brunswick, NJ: Transaction, 1987.

7. Schwartz WB, Mendelson DN: Hospital cost containment in the 1980s. New England Journal of Medicine 1991; 324:1037-1042.

8. Wells KB, Astrachan BM, Tischler GL, et al.: Issues and approaches in evaluating managed mental health care. Milbank Quarterly 1995; 73:57-75.

9. Folland S, Goodman AC, Stano M: The Economics of Health and Health Care. New York: Macmillan, 1993.

10. French MT, Dunlap LJ, Galinis DN, et al.: The Impact of Health Care Reforms and Managed Care on the Availability, Financing, and Costs of Substance Abuse Treatment. Final report (No. 271-912004) prepared for the National Institute on Drug Abuse. Research Triangle Park, NC: Research Triangle Institute.

11. Miller NA: An evaluation of substance misuse treatment providers used by an employee assistance program. International Journal of Addictions 1992; 27:533-559.

12. Gondolf E, Coleman K, Roman S: Clinical-based vs. insurance-based recommendations for substance abuse treatment level. Substance Use \& Misuse 1996; 31:1101-1116.

13. Lurie N, Moscovice IS, Finch M, et al.: Does capitation affect the health of the chronically mentally ill? Journal of the American Medical Association 1992; 267:3300-3304.

14. Eisenberg J: Doctors' Decisions and the Cost of Medical Care. Ann Arbor, MI: Health Administration Press Perspectives, 1986.

15. Dornbusch SM, Scott WR: Evaluation and the Exercise of Authority. San Francisco: Jossey-Bass, 1975.

16. Alexander JA, Lemak CH: The effects of managed care on administrative burden in outpatient substance abuse treatment facilities. Medical Care 1997; 35:1060-1068.

17. Zarkin GA, Galinis DN, French MT, et al.: Financing strategies for drug abuse treatment programs. Journal of Substance Abuse Treatment $1995 ; 12: 385-399$.

18. Dickey B, Azeni H: Cost-containment in mental health care: The role of utilization review. Advances in Health Economics and Health Services Research 1993; 14:197-207.

19. Price RH, Burke AC, D'Aunno TA, et al.: Outpatient drug abuse treatment services, 1988: Results of a national survey. In: Pickens RW, Lukefeld CG, Schuster CR (Eds.): Improving Drug Abuse Treatment. Rockville, MD: National Institute on Drug Abuse, 1991, pp. 63-92.

20. Rosko MD, Chilingerian JA, Zinn JS, et al.: The effects of ownership, operating environment, and strategic choices on nursing home efficiency. Medical Care 1995; 33:1001-1021.

21. Wheeler JRC, Fadel H, D'Aunno TA: Ownership and performance of outpatient substance abuse treatment centers. American Journal of Public Health 1992; 82:711-718.

22. Hansmann H: Economic theories of non-profit organizations. In: Powell WW (Ed.): The Nonprofit Sector: A Research Handbook. New Haven, CT: Yale University Press, 1987, pp. 27-42.

23. DeAlessi L: The economics of property rights: A review of the evidence. Research in Law and Economics 1980; 2:1-47.

24. Alchian AA, Demetz H: Production, information costs, and economic organization. American Economic Review 1972; 62:777-795.

25. Institute of Medicine [Gray BH (Ed.)]: For-Profit Enterprise in Health Care. Washington, DC: National Academy Press, 1986.

26. Marmor TR, Schlesinger M, Smithey RW: Nonprofit organizations and health care. In: Powell WW (Ed.): The Nonprofit Sector: A Research Handbook. New Haven, CT: Yale University Press, 1987, pp. 221-239.

27. Ozcan YA, McCue MJ, Okasha AA: Measuring the technical efficiency of psychiatric hospitals. Journal of Medical Systems 1996; 20:141-150. 
29. McCaughrin WC: The Relationship between Conformity to JCAHO Standards and Organizational Performance. Ann Arbor: University of Michigan Press, 1991.

30. Hubbard RL, Marsden ME, Rachal JV, et al.: Drug Abuse Treatment: A National Study of Effectiveness. Chapel Hill: University of North Carolina Press, 1989.

31. Alemi F, Stephens RC, Llorens S, et al.: A review of factors affecting treatment outcomes: Expected treatment outcome scale. American Journal of Drug \& Alcohol Abuse 1995; 21:483-509.

32. Feldstein P: Health Care Economics. Fourth ed. Albany, NY: Delmar, 1993.

33. McLaughlin C: Market responses to HMOs: Price competition or rivalry? Inquiry 1988; 25:205-218.

34. Joskow PL: The effects of competition and regulation on hospital bed supply and the reservation quality of the hospital. Bell Journal of Economics 1980; 38:48-58.

35. Lee ML: A conspicuous production theory of hospital behavior. Southern Economic Journal 1971; 38:48-58.

36. Hilsenrath PE, Chien RC, Rohrer JE: Implementing EACHs (essential access community hospitals) and RPCHs (rural primary care hospitals) on a statewide basis: A preliminary analysis. Journal of Rural Health 1991; 7:618-629.

37. Charnes A, Cooper WW, Rhodes E: Measuring the efficiency of decision-making units. European Journal of Operational Research 1978; 2:429-444.

38. Schinnar AP, Kamis-Gould E, Delucia N, et al.: Organizational determinants of efficiency and effectiveness in mental health partial care programs. Health Services Research 1990; 25:387-420.

39. Magnussen J: Efficiency measurement and the operationalization of hospital production. Health Services Research 1996; 31:21-37.

40. Fare R, Lovell CA: Measuring the technical efficiency of production. Journal of the Royal Statistical Society 1978; 19:151-162.

41. Banker RD, Charnes A, Cooper WW: Some models for estimating technical and scale inefficiencies in data envelopment analysis. Management Science 1984; 32:1078-1092.

42. Heeringa SG: Outpatient Drug Abuse Treatment Studies: Technical Documentation. Ann Arbor: University of Michigan, Institute for Social Research, 1996.

43. Groves RL (Ed.): Telephone Survey Methodology. New York: John Wiley, 1988.

44. Health Care Financing Administration: Prospective Payment System Payment Impact File. Washington, DC: Federal Register, 1997.

45. Onken LS, Blaine JD: Psychotherapy and counseling research in drug abuse treatment: Questions, problems, and solutions. In: Onken LS, Blaine JD (Eds.): Psychotherapy and Counseling in the Treatment of Drug Abuse. Rockville, MD: National Institute on Drug Abuse, 1990 , pp. 1-35.

46. Maddala GS: Limited-Dependent and Qualitative Variables in Economics. New York: Carnbridge University Press, 1983.

47. Breen R: Regression Models: Censored, Sample-Selection, or Truncated Data. Sage University Paper Series on Quantitative Applications in the Social Sciences, No. 07-011. Thousand Oaks, CA: Sage, 1996.

48. Greene WH: Econometric Analysis. Second ed. New York: Macmillan, 1993.

49. Wickizer TM, Wheeler JRC, Feldstein PJ: Have hospital inpatient cost containment programs contributed to the growth in outpatient expenditures? Analysis of the substitution effect associated with hospital utilization review. Medical Care 1991; 29:442-451.

50. Clement JP, Smith DG, Wheeler JR: What do we want and what do we get from not-for-profit hospitals? Hospital and Health Services Administration 1994; 39:159-178.

51. Vitaliano D, Toren M: Cost and efficiency in nursing homes: A stochastic frontier approach. Journal of Health Economics 1994; 13:281-300.

52. Charnes A, Cooper WW, Rhodes E: Evaluating program and managerial efficiency: An application of data envelopment analysis to program follow-through. Management Science 1981; 27:668-697. 